\title{
Physics of Anaesthesia Made Easy
}

\author{
Bhavna Gupta ${ }^{1 *}$ and Lalit Gupta ${ }^{2}$ \\ ${ }^{1}$ Department of Anaesthesia and Critical Care, AIIMS, India \\ ${ }^{2}$ Department of Anaesthesia and Critical Care, Maulana Azad Medical College, India
}

*Corresponding author: Bhavna Gupta, Department of Anaesthesia and Critical Care, AIIMS, Rishikesh, India

\begin{abstract}
Physics is an attempt to describe the fundamental laws of world around us. As anesthesiologists we deal with liquids and gases under pressure at varying temperature and volume. These inter relationships are simple, measurable and their understanding ensures a safe outcome for the patient. For the safe and efficient use of anesthesia apparatus, a basic knowledge of fundamental physics is must for a clear concept of their working principle. We have tried to simplify the basic physics related to anesthesia in a simplified way through the review article.
\end{abstract}

\section{Introduction}

\section{Basic Concepts}

\section{Units of Measurements}

(Table 1)

Table 1: Units of measurements.

\begin{tabular}{|c|c|c|}
\hline Basic SI Units & Derived Units & Units not in SI system \\
\hline length (meter) & $\begin{array}{c}\text { temp (degrees } \\
\text { Celsius) }\end{array}$ & pressure (mmHg) \\
\hline mass (kilogram) & force (newton) & pressure ( $\mathrm{cmH}_{2}$ 0) \\
\hline time (second) & pressure (pascal/ bar) & $\begin{array}{c}\text { pressure (standard } \\
\text { atmosphere) }\end{array}$ \\
\hline current (ampere) & energy (electron volt) & energy (calorie) \\
\hline $\begin{array}{c}\text { temp (kelvin) } \\
\text { power (watt) }\end{array}$ & $\begin{array}{c}\text { force (kilogram } \\
\text { weight) }\end{array}$ \\
\hline $\begin{array}{c}\text { luminous intensity } \\
\text { (candela) }\end{array}$ & frequency (hertz) & \\
\hline $\begin{array}{c}\text { amount of substance } \\
\text { (mole) }\end{array}$ & Volume (lliter) & \\
\hline
\end{tabular}

\section{Simple Mechanics}
a) $\quad$ kilopascal $=7.5 \mathrm{mmHg}$.
b) $1 \mathrm{Bar}=750 \mathrm{mmHg}$
c) 1 kilopascal $=10.2 \mathrm{cmH}_{2} \mathrm{O}$
d) $1 \mathrm{std}$ atmosphere $=101.325 \mathrm{kPa}$

e) 1 calorie $=4.18 \mathrm{~J}$

f) 1 -kilogram weight $=9.8 \mathrm{~N}$

g) Pounds / inch ${ }^{2}(\mathrm{PSI})$-Atmospheric Pressure (1 PATM=14.7PSI)

h) $1 \mathrm{Bar}=100 \mathrm{kPa}=$ Atmospheric pressure at sea level [1].

\section{Pressure}

a) Force $=$ mass $\mathrm{x}$ acceleration $=\mathrm{kgms}^{-2}=$ Newton

b) Pressure $=$ Force $/$ Area

c) 1 Pascal $=$ I Newton acting over $1 \mathrm{~m}^{2}$

Gauge pressure is defined as pressure which is measured when unknown pressure is measured relative to atmospheric pressure [2]. This pressure is used in measuring:

a) Blood pressure

b) Airway measurements

In order for fluid to pass out of the barrel of the syringe the same pressure must be developed in the syringe.

a) For a $20 \mathrm{ml}$ syringe (diameter $2 \mathrm{~cm}$ ) - pressure generated is $100 \mathrm{kPa}$; even this is 6 times more than SBP of $16 \mathrm{kPa}(120 \mathrm{mmHg})$. So, during Biers block, pressure in the vein during rapid injection can exceed systolic pressure, particularly if a vein adjacent to the 
cuff is present.

Bed Sores: for a $20 \mathrm{~kg}$ of patient mass supported on an area of contact of $100 \mathrm{~cm}^{2}(10 \times 10)$

a) $\quad$ Force $=196 \mathrm{~N}(20 \mathrm{~kg} \times 9.81)$; Pressure $=19.6 \mathrm{kPa}$

b) Normal SBP $=16 \mathrm{kPa}$, so there is always a risk of Ischemia

Similar concepts are applied for pressure relief valves and expiratory valves of anaesthetic breathing systems. Pressure in the circuit exerts a force on the diaphragm and when this force is greater that the force exerted by the valve, air escapes through the expiratory valve. They are typically low-pressure valves (50Pa).

\section{Fluid Mechanics}

Flow is defined as amount of fluid or gas passing in unit time. Flow becomes laminar to turbulent after Reynold number (defined below) reaches above a value of 2000 .

Reynold's number (Re): - is a dimensionless number and has no units and is defined as:

Velocity x pressure $\mathrm{x}$ density / viscosity

$$
R=v p d / \mu
$$

When

$\mathrm{Re}<2000$ - flow is laminar

Re $>2000$ - flow is turbulent

\subsection{Points to Remember}

a) Viscosity is an important parameter to determine laminar flow

b) Density is an important parameter to determine turbulent flow

c) Reynold's number of 2000 delineates laminar from turbulent flow.

\section{Laminar Flow}

Flow moves in a steady state with no turbulence or eddies. Flow is greatest in the mid center and zero in peripheral wall. Hagen Poiseuille Equation is used to determine laminar flow, defined as:

$$
Q=\pi(P 1-P 2) r 4 / 8 \eta l
$$

Where P1 - P2 = Pressure difference across the tube

$\mathrm{r} 4$ = Radius to the power of four

$=$ Viscosity

$\mathrm{L}=$ Length and $8=$ constant

\section{Clinical Relevance}

a) The endotracheal tube with size 7 has almost twice resistance as compared to sized 8.0 ETT b) Intravenous fluids: Intravenous fluids flow via laminar flow, and flow is determined by Hagen Poiseuille Equation. This means that flow is greater through a shorter and wider cannula as compared to cannula which are long and small when the same pressure is applied to it. That's why shorter and wider cannula such as 16 or $18 \mathrm{G}$ cannulas are preferred during resuscitation.

\section{Turbulent Flow}

Turbulent flow denotes a situation in which the fluid flows in an unpredictable manner with multiple eddy currents which are not parallel to the sides of the tube through which they are flowing. Flow is facilitated by irregularities, sharp angulation, corners and are predicted by density of gas. Reynold number is always greater than 2000.

\section{Clinical Relevance}

a) Kinked ETT or ETT connectors often result in turbulent flow.

b) Heliox (a mixture of $21 \%$ helium and $79 \%$ oxygen) is used to reduce density and thereby improve the flow and is used in respiratory tract obstruction. Helium is much less dense than nitrogen, which constitutes $79 \%$ concentration of air. In patients with upper airway obstruction, flow is through an orifice and hence more likely to be turbulent and dependent on the density of the gas passing through it. Therefore for a given pressure gradient (patient effort), there will be a greater flow of a low density gas (heliox) than a higher density gas (air).

c) There is laminar flow during quiet breathing which becomes turbulent during coughing and speaking thereby resulting in breathlessness or dyspnea.

d) According to, Hagen - Poiseuille's Law. flow is laminar at low flows in the flow meter, while at higher flows, the law applicable to turbulent flow is applicable [3].

\section{Critical Flow}

Critical flow for a typical anesthetic gas has approximately the same numerical value as the diameter of the airway concerned.

a) $9 \mathrm{~mm}$ ETT has a critical flow of $9 \mathrm{~L} / \mathrm{min}$ : Above $9 \mathrm{~L} / \mathrm{min}=$ turbulent flow

b) Air has a lower density than Nitrous Oxide - laminar flow prevails

c) Air flow through the smaller airways is slower - laminar flow predominates

\section{The Gas Laws}

a) Boyles Law

b) Charles Law

c) Third Perfect Gas Law

d) Dalton's Law of Partial Pressures 


\section{e) Universal Gas Constant}

Boyles law: Boyle's law is a gas law, stating that the pressure and volume of a gas have an inverse relationship, when temperature is held constant.

$$
\begin{aligned}
& \mathrm{PV}=\mathrm{k} \\
& (\mathrm{P}=\text { pressure, } \mathrm{V}=\text { volume, and } \mathrm{k}=\text { constant })
\end{aligned}
$$

Cylinder capacity of oxygen cylinder at atmospheric pressure $=10 \mathrm{~L}$

Absolute cylinder pressure $=138$ bar

Therefore, since,

$\mathrm{P} 1 \mathrm{~V} 1=\mathrm{P} 2 \mathrm{~V} 2$

$138 \times 10=1 \times V 2$

So, $\mathrm{V} 2=1380 \mathrm{~L}$

\section{Charles Law (Gay Lussacs Law):}

\section{a) Charles Law States that at Constant Pressure}

$\mathrm{V} \alpha$ Temp (i.e. Gases expand when heated)

Clinical relevance- respiratory gas measurements are done at ambient temperature while exchange of gases rakes place at room temperature i.e. $37^{\circ} \mathrm{C}$

\section{b) Third Perfect Gas Law}

At constant volume, absolute pressure of a mass of gas varies directly with temperature.

\section{P $\alpha$ Temp}

\section{Clinical Relevance}

a) Medical gases are stored in cylinders having a constant volume and high pressures (138 Barr in a full oxygen/air cylinder). If these are stored at high temperatures, pressures will raise causing explosions.

b) Adiabatic changes: it is a change which doesn't involve transfer of heat $(Q)$ or matter into and out of a system, so that $Q=0$, and such a system is said to be adiabatically isolated.

Clinical Relevance: When a valve of an oxygen cylinder is opened suddenly, oxygen will rush into high pressure hose or stem of oxygen regulator and on reaching the end of hose, adiabatic process might occur. That suggests that local pressure is much higher than that of filling pressure of the cylinder (about 150 bar) for a very brief time. The process is adiabetic because compression occurs without any heat from outside and the effect can lead to sudden explosion if there is dust or grease at regulator preventing further gaseous expansion.

Dalton's Law of Partial Pressures: It states that in a mixture of gases, the pressure exerted by each gas is the same as that which it would exert if it alone occupied the container

Universal Gas Constant: Ideal Gas law is deduced by combining all 3 perfect gas laws and combining with the avogadro's hypothesis the concept of mole gives us the Universal Gas Constant $=\mathrm{R}$.

$$
\mathrm{PV} / \mathrm{T}=\text { Constant }
$$

For one mole of any gas (molecular weight expressed in grams)

$$
\mathrm{PV}=\mathrm{n} \text { RT }
$$

Where $\mathrm{R}=$ Universal Gas Constant

$\mathrm{n}=$ Number of moles

Avogadro's Hypothesis: States that equal volumes of gases at the same temp and pressure contain equal number of molecules. One mole of any gas occupies 22.4L at STP (standard temperature and pressure). Avogadro's number is defined as the number of elementary particles (molecules, atoms, compounds, etc.) per mole of a substance. It is equal to $6.022 \times 10^{23} \mathrm{~mol}^{-1}$ and is expressed as the symbol $\mathrm{N}_{\mathrm{A}}$.

\section{Clinical Relevance}

Nitrous oxide cylinder contains $3.4 \mathrm{~kg} \mathrm{~N}_{2} \mathrm{O}$

Mol wt. of $\mathrm{N}_{2} \mathrm{O}=44$ (1mole)

1 mole occupies 22.4 L at standard temp and pressure

Therefore 3400 g occupies 22.4 x 3400/44 = 1730L

\section{Solubility Mechanics}

Solubility Saturated vapor pressure is defined as the partial pressure exerted by vapour in the equilibrium state is achieved at the surface between vapor of the liquid and liquid itself when a liquid is placed in a closed container. SVP is associated with Henry's law [4].

Henry's Law states that at a temp, the amount of a given gas dissolved in a given liquid is directly proportional to the partial pressure of the gas in equilibrium with the liquid.

a) Bubbles may be seen when a liquid is warmed and less gas dissolves in it.

b) The effect of high pressure is particularly relevant to deep sea divers as the solubility of nitrogen if breathed under pressure passes into solution in the tissues. If a return to atmospheric pressure is made too rapidly, the nitrogen comes out of solution as small bubbles in the joints and tissues causing pain and bends.

Ostwald Solubility Coefficient is the volume of gas which dissolves in one-unit volume of the liquid at the temp concerned (Independent of pressure) Ostwald solubility coefficient of ether is highest, and the value is 12 . Halothane has solubility coefficient of 2.3 and that of nitrous oxide is 0.47 . So, ether used to be carried 
away very slowly and its concentration to build up in alveoli was very slow thereby leading to slower induction of anesthesia.

Blood: Gas Solubility Coefficient: the ratio of the amount of substance in equal volume phases of blood and gas in a closed system at equilibrium and at standard temperature and pressure.

Oil: Gas Solubility Coefficient: the ratio of the amount of substance present in equal volume phases of oil and gas in a closed system at equilibrium and at standard temperature and pressure.

Clinical Relevance: Agents with the highest oil solubility have the greatest potency and lower MAC value and forms the basics of Meyer Overton theory of anesthesia Table 2.

Table 2:

\begin{tabular}{|c|c|}
\hline $\mathrm{N}_{2} \mathrm{O}$ & $\mathbf{1 . 4}$ \\
\hline Ether & $\mathbf{6 5}$ \\
\hline \multirow{3}{*}{ Halothane } & 224 \\
\cline { 2 - 2 } & $\begin{array}{c}\text { (very potent and needs lesser } \\
\text { concentration in alveoli and brain) }\end{array}$ \\
\hline
\end{tabular}

Diffusion: Diffusion is a process in which the molecules of a substance (such as gas) transfer through a layer such as the surface of a solution to another one.

Grahams Law states that the rate of diffusion of a gas is inversely proportional to the square root of its molecular weight.

\section{Clinical Relevance}

a) Thus, heavier gas will diffuse more slowly. Also, if the MW (molecular weight) of a gas is four times of another, it would diffuse at half the rate of the other.

b) Local anesthetics injection for nerve block should be done as proximity to the nerve as diffusion only allows limited penetration of the LA into the tissues.

c) Heliox mixture of helium and oxygen, is a lighter gas, hence is used in airway obstruction to improve diffusion and gas exchange.

\section{Fick's Law of Diffusion:}

The rate of diffusion of a gas across a membrane is directly proportional to the membrane area (A) and the concentration gradient $\left(\mathrm{C}_{1}-\mathrm{C}_{2}\right)$ across the membrane and inversely proportional to its thickness (D).

Rate of diffusion $\alpha$ A $\left(\mathrm{C}_{1}-\mathrm{C}_{2}\right) / \mathrm{D}$.

\section{Clinical Relevance}

a) Anesthetic vapors diffuse into breathing circuits and later acting as Vaporizers at the time of discontinuation of anesthetic gases.

b) $\mathrm{N}_{2} \mathrm{O}$ gas diffuses into cuff of endotracheal tube.

c) Diffusion of $\mathrm{N}_{2}$ Ointo airfilled cavitiesasin pneumoecephalous, pneoumoperitoneum etc.
Concentration Effect and Second Gas Effect: At the time of inspiration, Nitrous oxide is absorbed into blood stream at a faster rate than oxygen or nitrogen gas. At the peak of inspiration, when pressure in the alveoli equalizes with the ambient pressure, there is net surpulous supply of oxygen and nitrogen molecules. This results in effects known as the "concentration effect" and the second gas effect. When a constant concentration of an anesthetic such as sevoflurane is inspired with nitrous oxide, the alveolar concentration of sevoflurane is accelerated due to nitrous oxide, because alveolar uptake of the latter creates a potential sub atmospheric intrapulmonary pressure that leads to increased tracheal inflow.

Diffusion Hypoxia: Nitrous oxide diffuses faster from the alveoli at the end of anesthetic exposure, as $\mathrm{N}_{2} 0$ diffuses faster into the alveoli thereby diluting the gases leading to fall in oxygen saturation, also known as diffusion hypoxia, therefore $100 \%$ oxygen is required at the end of surgery to avoid diffusion hypoxia.

\section{Osmolarity}

It is defined as the sum total of the molarities of the solutes in a solution.

a) Ringer Lactate has an osmolarity of $278 \mathrm{mosm} / \mathrm{l}$

Constituents of RL

Na $131 \mathrm{mosm} / \mathrm{l}$

$\mathrm{K} 5 \mathrm{mosm} / \mathrm{l}$

Cl 111mosm/l

Ca $2 \mathrm{mosm} / \mathrm{l}$

Lactate $29 \mathrm{mosm} / \mathrm{l}$

Plasma has an osmolarity of $275-295 \mathrm{mosm} / \mathrm{kg}>99 \%$ due to $\mathrm{Na}, \mathrm{Cl}, \mathrm{HCO}_{3}$.

\section{Energy Mechanics}

Heat Capacity: Heat Capacity is defined as the amount of heat required to raise the temperature of a given object by 1 kelvin.

\section{Specific Heat Capacity}

Specific Heat Capacity defined as the amount of heat required to raise the temperature of $1 \mathrm{~kg}$ of a substance by 1 kelvin. $(\mathrm{J} / \mathrm{kg} /$ Kelvin)

\section{Clinical Relevance}

Normal body temperature is 36 degrees Celsius and basal heat production is $80 \mathrm{~W}(\mathrm{~J} / \mathrm{Sec})$

Shivering increases heat production by 4 fold (ie $320 \mathrm{~W}$, with extra $240 \mathrm{~W}=14.4 \mathrm{~kJ} / \mathrm{min}$ ) $245 \mathrm{~kJ}$ needed to increase temp by 1 degree (total heat capacity $=3.5 \times 70 \mathrm{~kg}$ ), so patient has to shiver for approximately $245 / 14.4=17 \mathrm{~min}$ to produce this extra heat. 


\section{Bernoulli's Principle}

It is defined by the law of conservation of energy. Flowing liquid possess 2 types of enrgy- potential and kinetic energy. If there is a constriction in tube, there is increase in kinetic energy, there is subsequent fall in potential energy, to conserve the total energy [4].

\section{The Venturi Effect}

Venturi effect was named after famous Italian physicist, Giovanni Battista Venturi (1746-1822). It is the effect by which the introduction of a constriction to fluid flow within a tube causes the velocity of the fluid to increase, therefore, the pressure of the fluid to fall. By measuring the change in pressure, the flow rate can be determined, as in various flow measurement devices such as venturi masks, venturi nozzles and orifice plates.

a) The Venturi effect may be observed or used in the following:

b) The capillaries of the human circulatory system, where it indicates aortic regurgitation.

c) Injectors used to add chlorine gas to water treatment chlorination systems.

d) Ventilators.

\section{Conada effect}

If a constriction occurs at bifurcation because of increase in velocity and reduction in the pressure, fluid (air, blood tends to stick to one side of the branch causing maldistribution.

a) Mucus plug at the branching of tracheo-bronchial tree may cause maldistribution of respiratory gases.

b) Unequal flow may result because of atherosclerotic plaques in the vascular tree.

c) Fluid logic used in ventilators employs this principle to replace valves or mobile parts.

\section{Spectrophotometry- Basic Concepts}

\section{a) Beers Law}

Beer law states that amount of light absorbed is proportional to the concentration of the light absorbing substance.

\section{b) Lamberts Law}

Equal thicknesses absorb equal amounts of radiation. Amount of light absorbed is proportional to the length of the path that the light has to travel in the absorbing substance. Both laws say that the absorption of radiation depends on the amount of a particular substance. This fact has been utilized in pulse oximetry.

Pulse 0ximetry: It involves Spectrophotometry \& Plethysmography.

a) Light absorbed by the blood depends on the quantities of Haemoglobin and Deoxy-Hb and the wavelengths of the light.
Absorbance of $\mathrm{Oxy}-\mathrm{Hb}$ at wavelengths of $660 \mathrm{~nm}$ (red light) is less and that of DeOxy-Hb is less in 940nm (blue light)

b) Two diodes, one emitting red light $660 \mathrm{~nm}$ and the other a blue light $(940 \mathrm{~nm})$ are positioned so that they are opposite their respective detectors through $5-10 \mathrm{~mm}$ of tissue. The output processed electronically on the other side of the finger gives the oxygen saturation depending on the relative amount of each type of $\mathrm{Hb}$ present in the pulsating arterial blood.

c) More the Hb per unit area more is the light is absorbed. This property is described in a law in physics called "Beer's Law". While, longer the path the light has to travel, more is the light absorbed. This property is described in a law in physics called "Lambert's Law.

\section{Capnography and Anesthetic Analyzers}

a) Both mainstream and side stream capnometers rely on absorption spectroscopy and, accordingly, on Beer-Lambert law.

b) In side stream type infrared absorption spectroscopy, respiratory gas analyzers are usually integrated in the anesthesia machine. These devices use different wavelengths appropriately chosen to measure, in addition to $\mathrm{pCO}_{2}$, the concentration of other respiratory gases such as nitrous oxide, and different volatile anesthetics (anesthetic analyzers) [5]

\section{Circulation}

Hemodynamics can be defined as the physical factors that govern blood flow. These are the same physical factors that govern the flow of any fluid and are based on a fundamental law of physics.

\section{Ohm's Law}

a) Pressure $=$ Flow $x$ Resistance

b) Voltage $=$ Current $x$ Resistance

c) $\quad$ Resistance $=$ Pressure $/$ Flow

\section{Law of Laplace}

Tension may be defined as the internal force generated by a structure, La Place Law states that for cylinders,

$\mathrm{T}=\operatorname{Pr}$

(where $\mathrm{T}$ = wall tension, $\mathrm{P}$ = pressure of fluid within the cylinder, $r=$ radius

Ohm's Law: It states that current (I) equals the voltage difference $(\Delta V)$ divided by resistance (R). In relating Ohm's Law to fluid flow, the voltage difference is the pressure difference $(\Delta \mathrm{P}$; sometimes called driving pressure, perfusion pressure, or pressure gradient), the resistance is the resistance to flow (R) offered by the blood vessel and its interactions with the flowing blood, and the current is the blood flow (F). This hemodynamic relationship can be summarized by:

$$
F=\frac{\Delta \mathrm{P}}{R}=\frac{\left(\mathrm{P}_{A}-\mathrm{P}_{V}\right)}{R}
$$


a) For the flow of blood in a blood vessel, the $\Delta \mathrm{P}$ is the pressure difference between any two points along a given length of the vessel. When describing the flow of blood for an organ, the pressure difference is generally expressed as the difference between the arterial pressure (PA) and venous pressure (PV).

\section{Law of Laplace (Wall Stress):}

Laplace Law states that for cylinders,

$\mathrm{T}=\operatorname{Pr}$ or $\mathrm{P}=\mathrm{T} / \mathrm{r}$ (e.g. Arteries)

For sphere,

$\mathrm{P}=2 \mathrm{~T} / \mathrm{r}$ (e.g. Anesthesia Bag/ Heart)

(Where $\mathrm{T}=$ wall tension, $\mathrm{P}=$ pressure of fluid within the cylinder / sphere, $r$ = radius);

Tension may be defined as the internal force generated by a structure.

\section{Clinical Relevance}

a) In a failing heart -there is an increase in radius therefore a decrease in pressure, and failing heart is unable to increase T.

b) In a normal heart, increase in radius is beacuase of increase in venous return, also there is increase in Tension according to Frank starling law. Therefore there is no change in pressure.

c) The management of stable angina is to reduce wall stress thereby decreasing myocardial oxygen demand.

d) In a patient with chronic hypertension, there is overall increase in left ventricular wall thickness to compensate for increased wall stress.

e) Left ventricular pressure increases with symptoms of increased "afterload" of the heart, including systemic hypertension and aortic valve stenosis.

\section{Miscellaneous Physics}

\section{Archimedes' Principle}

Archimedes' principle is a law of physics fundamental to fluid mechanics. It says any object, wholly or partially immersed in a stationary fluid, is buoyed up by a force equal to the weight of the fluid displaced by the object.

a) Air Bubbles: According to Archimedes' principle, air bubbles always tend to go upward in any liquid, including saline, drugs, and blood. So, just keep up the cone of the syringe (exit path), bubbles can be removed by ejecting air by pushing the plunger of syringe.

b) Cardiac Surgery: During cardiac surgery, de-airing is done before aortic de-clamping in order to prevent air bubbles from reaching the brain. If de-airing is performed through a ventriculotomy, the anesthesiologist is asked to place the patient in the Trendelenburg position, so that the venting site is located above and air expulsion is favored.

c) Archimedes' principle helps cardiac anesthesiologists to prevent (or reduce) cerebral air embolism when air accidentally enters the circuits during cardiopulmonary bypass (CPB) by immediately placing the patient in steep Trendelenburg position.

\section{Calculating the Duration of a $\mathrm{N}_{2} \mathrm{O}$ Cylinder}

Just Now a new $\mathrm{N}_{2} \mathrm{O}$ cylinder is fitted to the Machine. How Long Will It Last...? Can a case of 6 hrs duration be taken with this cylinder?

First step is to calculate the Amount of $\mathrm{N}_{2} \mathrm{O}$ Gas in Cylinder?

a) Atomic weight of nitrogen - 14, oxygen - 16,

Molecular weight of $\mathrm{N}_{2} \mathrm{O}=14+14+16=44$

b) As per AVAGADRO Hypothesis:

one-gram molecular weight of all gases will contain the same number of molecules and occupy the same volume (22.4 l) at STP.

So,

$32 \mathrm{~g}$ of $\mathrm{O}_{2}=44 \mathrm{~g}$ of $\mathrm{N}_{2} \mathrm{O}=28 \mathrm{~g}$ of $\mathrm{N}_{2}=22.4 \mathrm{Lt}$.

Empty weight of the cylinder $=12.5 \mathrm{Kg}$, Cylinder weight with $\mathrm{N}_{2} \mathrm{O}=15 \mathrm{Kg}$

So,

Weight of the $\mathrm{N}_{2} \mathrm{O}=2.5 \mathrm{Kg}=2500 \mathrm{~g} ; 44 \mathrm{~g}$ of $\mathrm{N}_{2} \mathrm{O}=22.4 \mathrm{Lt}$ (Avogadro hypothesis)

Therefore $2500 \mathrm{~g}=22.4 / 44 \times 2500=1272 \mathrm{Lt}$.

So, amount of duration for which a $\mathrm{N}_{2} \mathrm{O}$ cylinder can be used $=$ $1272 \mathrm{Lt} /$ flow of $\mathrm{N}_{2} \mathrm{O}$ on machine per minute.

(Suppose the flow of $\mathrm{N}_{2} \mathrm{O}$ is $3 \mathrm{Lt} / \mathrm{m}=180 \mathrm{Lt} / \mathrm{hr}$, so the cylinder will last for $1272 / 180=07 \mathrm{hr}$ ).

\section{Unexpected Help from the Reservoir Bag}

The reservoir bag in an anesthesia machine allows manual ventilation as well as a "visual" monitoring of spontaneous breathing.

a) Thanks to Laplace's law, it can prevent barotrauma in case of malfunction or unintentional closing of the APL (adjustable pressure limiting) valve. In fact, in the presence of an overflow or a flow obstruction in the breathing system, the radius of the reservoir bag increases (Figure 5) and, according to Laplace's law, the pressure inside it decreases $(\mathrm{P}=2 \mathrm{~T} / \mathrm{R})$, thus preventing a dangerous rise in pressure in the entire breathing system and, consequently, in lungs.

b) Accordingly, a reservoir bag which feels stiff should be replaced, since its wall tension (which we can define, similarly to surface tension $\gamma$, as the work required to extend the surface of an 
elastic membrane by a unit area will be higher, for the same radius (or its radius will increase by a lesser extent for the same value of wall tension), thus providing a lower "pressure relief".

\section{Conclusion}

Anesthesia has evolved very fast over last few decades but the basic are still same and applicable in day to day anesthesia instruments and apparatus. It is necessary to understand the basic physics behind every anesthetic instrument, so that it becomes easy to operate. Learning conceptual physics also helps to trouble shoot the problem associated with them.

\section{References}

1. Fundamentals of Anesthesia, $\left(2^{\text {nd }} e d n\right)$.

2. Understanding Anesthesia equipment by Dorsch and Dorsch, $\left(5^{\text {th }}\right.$ edn).

3. Physics, Pharmacology and Physiology for Anesthetists, $\left(2^{\text {nd }} e d n\right)$.

4. Basic physics and measurement in anaesthesia, ( $4^{\text {th }}$ edn $)$.

\section{(c) \\ This work is licensed under Creative Commons Attribution 4.0 License}

To Submit Your Article Click Here:

Submit Article

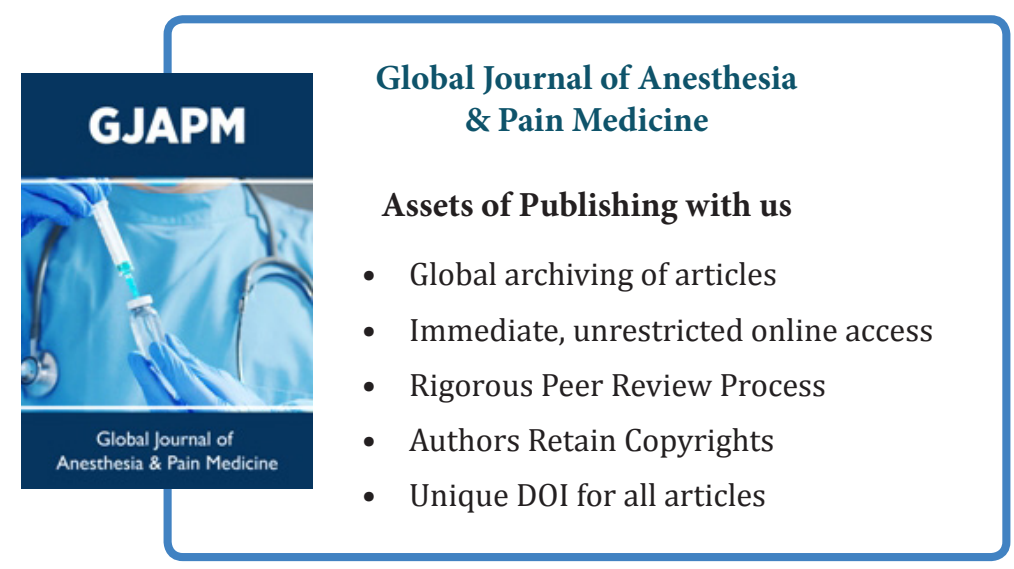

